\title{
Effect of Substance Abuse on Nigeria's Economic Performance
}

\author{
Ikhayere Jossy Ijie ${ }^{1}$, Abdurrauf Babalola ${ }^{2}$, Muhammad Yelwa ${ }^{3}$ \\ ${ }^{1}$ Area Commander, National Drug Enforcement Agency, Area 3, Abuja, FCT. Nigeria \\ ${ }^{2}$ Department of Economics, Alhikmah University, Ilorin. Nigeria \\ ${ }^{3}$ Department of Economics, University of Abuja, FCT. Nigeria
}

\section{ABSTRACT}

Keywords: Drug Abuse, Narcotic, Rehabilitatedindividual, Substance Abuse, Nigeria.
Purpose of the study: This study investigated the effect of substance abuse on the real growth rate in Nigeria between 1993 and 2017. The study specifically examined the period-based impact of substance abuse prevalence and rehabilitated individual drug addicts on the actual growth rate of the Nigerian economy.

Methodology: Autoregressive distributed lag and co-integration/bound test techniques were employed to analyze the data obtained. In between, correlation analysis and preliminary tests were carried out.

Main findings: The study found out that substance abuse and rehabilitated drug individuals have a significant impact on economic performance. While substance abuse has a significant negative impact, rehabilitated, individual drug addicts have a significant positive impact. However, in the long run, there was no indication of a significant impact on the Nigerian economy.

Research limitations/implications: This study will be of use to the National Drug Law Enforcement Agency, the United Nations Office on Drugs and Crime, the National Institute on Drug Abuse, and most drug control programs in many countries. The Ministries of Economic Planning to examine the extent to which drug abuse has had an economic impact.

Novelty/Originality of this study: Economic analysis showcasing the effect of drug abuse prevalence and rehabilitated individuals on economic performance is quite scanty. This work creates a good reference point in areas of health economics and macroeconomics generally. It allows readers to know the genesis of drug trafficking and abuse in Nigeria.

\section{INTRODUCTION}

Current evidence from around the world appears to reveal a continuing upward trend in the abuse of trafficking in narcotic and psychotropic substances. Drug abuse and trafficking among adolescents and young adults have existed for decades. However, in recent years the proportion has grown at a disturbing rate over the past two decades crossing all social-economic, political, and national boundaries.

World drug report shows that around 210 million people, aged 15-64 years, consume illicit drugs annually. Out of this number, problem drug users account for 27 million, and millions die from illicit drugs and alcohol abuse annually (UNODC, 2011). One pointer of the extent of abuse of drug and trafficking in the economic term is the estimates of the international illicit drug industry. According to Global Financial Index (GFI), the global market in drug trafficking has a projected annual global worth of between $\$ 426$ billion and $\$ 652$ billion (USD), which makes this market next to counterfeit and pirated goods as a most lucrative illicit market. It is expected to generate as much as $\$ 1.13$ trillion annually (GFI, 2017). There continue to be an unsatisfied and huge desire for drug abuse stoppage, cure, care, and sustenance, particularly in countries that are just developing. Drug use affects not only the individual user but also their families, friend, coworkers, and communities. The abuse/use of these drugs cut across culture, social, political background, sex, age, and religion. In some quarters, it is not only seen as a health or social problem but a threat to human existence.

Africa is largely involved in the illicit drug trade. For instance, illegal drug consumption in South Africa doubles the world norms with the largest illegal drug markets in Sub-Saharan Africa. The figure circulated by the South African Police service shows that drug abuse account for about $60 \%$ of all crimes, and $15 \%$ of South Africans abuse drugs (South African Depression / Anxiety Groups, 2013). In 1996, an estimated 3.6 million Nigerians had drug abuse problems (NDCMP, 1999). In 2018, a study steered by the National Bureau of Statistics (NBS) established the huge scale of Nigeria's drug challenge. The survey indicates that, in 2017, approximately 15 percent of the adult population in Nigeria (around 14.3 million people) reported a mandatorily significant level of use of psychotropic substances. This report becomes worrisome because it doubles the global 2016 average of 5.6\% among adults (Yomi, 2019). Despite various measures undertaken by law enforcement agencies, the relative ease with which youths are able to obtain all forms of illicit drugs is disturbing. This appears to be a fall out the effect of drug trafficking in Nigeria being used as a conduit pipe in the international narcotic drug trade. Local markets for narcotic drugs are being created in the major cities of Nigeria. Youths exposed to drug abuse often develop social, physical, psychological, and economic problems. Lives are lost daily through addiction and activities of drug traffickers. A huge number 
of violent crimes and uncountable deaths from accidents have been traced to the activities of persons influenced by drugs. The increase in the number of international conferences, symposia, and seminars on drug problems reflect the concern over the widespread abuse of drugs in many countries of the world, including Nigeria.

\subsection{Stylized Facts about Substance Abuse in Nigeria.}

Government of Nigeria has been sincerely worried about the extent of and the rising tendency in the demand for and traffic in narcotic drugs and psychotropic substances, which unfavorably affect the international image of the country and the wellbeing of her citizenry. Distinguishing the relationship between illicit traffic in drugs and psychotropic substances and other related prearranged crimes that destabilize and demoralize the real economy and impend the stability and security of the country within the sub-region is a thing of great concern. Nigeria has been in the vanguard of international efforts at reducing the drug menace in support of the region as well as global peace and security.

The problem of drug abuse started to shoulder a very worrisome dimension in the late forties, subsequent to the return of some Nigerian soldiers from mainly Burma and India, where they participated in World War II. Among the spoils of war, the militaries were said to have returned with, were some seeds of cannabis sativa, also known as India Hemp, which they, after that, carried out trial and discovered that the illicit plant would thrive in some parts of the country. With time, the growing of cannabis began to develop exponentially alongside the trafficking and abuse of the plant, which is described by many drug analysts as the "wicked weed." By early 1990, those engaged in the nefarious illicit drug business rapidly realized that the topographical location of Nigeria, its dense population, busting business and animated air transport activities, give room for a striving drug trade such as "Category A" drugs which include Cocaine, Heroin, and other psychotropic materials, into the country.

The drug data statement of the National Drug Law Enforcement Agency (NDLEA) shows that all categories of illicit drugs are widely abused in all the states of the federation including the Federal Capital Territory (FCT). The 1999 rapid situation assessment of the drug problem in Nigeria undertaken by NDLEA/United Nation Development Program (UNDP) in 22 states of the federation covering the six geopolitical zones, revealed that cannabis is the drug most abused by all categories/ class of people in the society (NDLEA, 2017). These were mainly secondary and tertiary students, commercial sex workers, artisans, professionals, unemployed youths, journalists, religious leaders, law enforcement personnel, prison inmates, among others.

These drugs are not produced in Nigeria but are brought from Asia and South American countries. Thus, Nigeria serves not only as a consuming nation but an international-transit point for illicit trafficking to Europe and America. The fall out of the effects of this illicit trade in Nigeria is the creation of local markets for the sale and consumption of cocaine and heroin. Of note is also the rising trend of consumption of diverse groups of chemicals that produce psychoactive vapors readily abused mostly in the northern part of the country. Examples of these chemicals include aerosols, gasoline, glue, nail removal, insecticides, among others. NDLEA annual reports indicated that drug abuse and illicit cannabis cultivation and trafficking have, over the years following some observable social parameters such as gender, age, ethnicity, and social class. The report shows that between the years 2000 and 2010, a total of 48,728 males and 3,226 females were arrested and prosecuted. The report also indicated that most of the people arrested for cross border illicit drug trafficking come from the South-East, South-South, and Southwest with the occasioned arrest of persons from the other part of the country. At the same time, the North-West and southeast are categorized as highest in drug abuse followed by South-South, North-Central, North-East, and South-West in that order (NDLEA, 2017). The same report indicated that 8,826 suspected drug offenders made up of 8,332 males and 494 females were apprehended in 2014 alone. The total quantity of drugs seized stood at $166,677.18 \mathrm{~kg}$. As usual, cannabis maintained the lead of the total drug seizure with $158,852.20 \mathrm{~kg}$, while psychotropic followed with 7,407.20kg, Cocaine $222.04 \mathrm{~kg}$, Heroin 56.449 $\mathrm{kg}$, Methamphetamine $119.2 \mathrm{~kg}$., Ephedrin $35.8 \mathrm{~kg}$. Sad enough is the discovering of over ten clandestine illicit drug laboratories in Anambra and other parts of the country in 2015 and 2016 alone, which now earned the country the opprobrium of a drugproducing nation (Mitchel, 2015).

Drug abuse in Nigeria is not predominantly male affairs, women are largely involved. Between the years 2000-2010, a total of 48,728 males were arrested with 3,226 females (NDLEA seizure report, 2015). This is a significant drain on the labour force and human capital resources. Because when traffickers are incarcerated, they are unable to participate in labour supply, thereby crowding out productivity.

The social and economic costs relating to drug abuse in Nigeria are high. These include the financial losses and distresses suffered by drug-related crime victims, increased burden for the support of the addicts, and greater demand for medical and other treatment services. There is also a more significant loss of potential manpower leading to poor economic performance and the creation of a volatile environment for investors, all leading to lowered GDP in the country. Botvin decried the involvement of Nigeria youths in drug trafficking and crimes, which impairs Nigeria's image both at home and abroad. To him, such individuals constitute a menace to the society and become social deviants and economically dependent, rendering the labour market vacant (Botvin, 1995).

The drug data report of the NDLEA showed that all categories of illicit drugs are widely abused in all the states of the federation. The data revealed that cannabis is the most commonly abused by all class of people in the society-artisans, professionals, civil 
servants, journalists, religious leaders, health workers, traders, and law enforcement agents who constitute the labour force. High productivity in an economy is a function of healthy labour force (NDLEA, 2017).

The unsavory phenomenon of illicit drug use and abuse calls for the societal dedication of resources to evidence-based prevention strategies and interpolation, which include treatment, rehabilitation, and public enlightenment program. The Nigeria government expended \#500 million in 2008 alone in drug abuse enlightenment in all the six geopolitical zones of the country (Mitchel, 2015). Although such preventive measures can be expensive, studies have shown that for every $\$ 1$ expenditure made, earn effective prevention program would save the government up to $\$ 10$ in subsequent cost (INCB, 2012). In 2012, about 1,404 hectares of farmlands used for the cultivation of cannabis were discovered and destroyed by drug law enforcement agency in Nigeria, while illicit drug seized weighed $33,968 \mathrm{~kg}$ with a projected street worth of \#34 billion naira which was roughly the half of national budget for agriculture that year. For sure, when these illicit drugs are seized by law enforcement and destroyed through public burning, investments on them by farmers are nullified. Despite ever-increasing budgetary allocation and expertise in drug abuse control in the country, there is yet a sporadic increase in the drug problem in both demand and supply.

\section{LITERATURE REVIEW}

\subsection{Conceptual Review}

Most definitions of substance abuse available in the literature are not usually expressed in economic terms but in public health, medical, and criminal justice context. For example, The National Institute on Drug Abuse (NIDA), puts the meaning of drug addiction as a prolonged, lapsing malady characterized by habitual drug search and consumption even with opposing implication (NIDA, 2018). A definition expressed in the epidemiological term is that drug abuse is considered to happen when a relevant etiological division is larger than zero, that is, when drug abuse harmfully affects the health of the consumer (Eric et.al, 2000). A more and all-inclusive definition within the realms of economics and sociology, which cuts across non-medical costs such as accidents and policing, is that abuse exists when drug use, most often illicit drugs, and involves a net social cost in addition to the resource cost of the provision of that drug. That is, substance abuse arises if the society incurs net cost as a result of drug use.

Specifically, substances are abused by individuals when they are consumed in a different way from medically recommended or socially acceptable forms within the society. Simply put, the drug is said to be abused when its use is not medically necessary, or it is used for non-medical purposes; its use is legally prohibited, or it is excessively used as in the case of a socially acceptable drug like alcohol.

\subsection{Theoretical Review}

National governments and business communities are increasingly and continuously recognizing the undesirable consequences of substance abuse on their economies and the national labour force. The impact of illicit drug use on our national economies and the health of people who use drugs are notorious. The preventive measures are undertaken by the government, production, and preparation of illicit drugs by traffickers and care, rehabilitation, and social reintegration process by addict families are serious financial and economic drains (Ijie, 2016). It is generally accepted that substance use and abuse by workers could harmfully affect their performance and the productivity of workplaces and invariably cut down the national output of that society (Eric et. al. 2000).

Drug abuse occurs most often among people in the 15-55 years' age cluster (UNODC, 2017). In essence, it includes those within the labour force. Given the high unemployment rate in most developing countries like Nigeria, gainful employment is often a major problem. Abuse of illegitimate drugs edges the probability of entering or remaining in the employment sector, while thwarting initiated by the inability to find job favours drug intake, thus crafting a vicious circle (Ijie, 2019). Alcohol and drug abuse by employees will cause many expensive problems for business and industry, ranging from low productivity, workplaceaccident, injuries, an increase in health care, and insurance claims, to mention few.

The extrapolated economic cost (externalities) of drug abuse in the U.S. was put at \$195 billion in 2007 . This cost includes $\$ 120$ billion in lost of productivity, mainly due to labour involvement cost, care for drug abuse victims, detention and premature death, $\$ 11$ billion in health care cost, and \$61 billion in criminal justice which included criminal investigation, prosecution, and incarceration ( UNDCP, 2009). These costs incurred have an opportunity cost, which is the next best sector the government would have spent on, if not spent on the management and control of drug abuse-related issues.

Drug abuse in the workplace imposes a substantial extra cost on the trade industry, thus decreasing its competitiveness. Despite its current level of development, society will find it extremely difficult to advance if it has to be dependent on a workforce that is weakened by large scale drug use and abuse. The consequence of illicit drug use on productivity depends on the type, qualities of drugs consumed, and performance required of the job in question. Responsibilities that involve high-level judgment, persistent attention, instant reminiscence and remembrance, and fine motor skills are apparently more easily messed up by drugs than physical labour. 
The correlation between low productivity, accidents, and drug-taking habits are also well well-known in many parts of the world today. Drug and alcohol-related issues in the workplace are not only costing Australian business money in absenteeism but also a ponderous $\$ 6$ billion in lost productivity (Kristin, Synnove \& Torleif, 2018). Further to the direct financial cost business suffers, there are concerning health issues that provide further stresses in the workplace. Drug issues cause a multi-billion randdent in the South African economy annually. The yearly expenditure to the country's alcohol abuse only, in the areas of absenteeism, reduced efficiency, health, and welfare cost, as well as alcohol connected misconduct are projected at up to $10 \%$ of GDP or as much as R37.9 billion annually, according to 2014 study in the South African Medical Journal (SAMJ). The newest investigation from the Medical Research Council (MRC), issued in the South African Medical Journal, indicates that South Africa lost approximately $\$ 23$ billion in 2009 as a result of alcohol abuse. It was said that around \$3 billion of the said amount was spent on tackling the social ills linked with alcohol-induced challenges, which include road accidents, disabilities, illnesses, and deaths as well as crimes. Health care services received the second-largest bill $\$ 930$ million, followed by social welfare at $\$ 30$ million, according to the MRC study (Forbes Africa, 2017).

Examining illicit drug use and abuse relating to productivity outcomes is essential for policies and researches geared towards checking drug challenges, and ascertaining its correlation with micro and macro level of labour market outcomes and economic performance as a whole is also apt in our present days (Roldes, 2014). Recent studies indicate that there seems to be a correlation between substance abuse prevalence and labor productivity and hence economic growth (Ijie, 2019; Roldes 2014; Eric, 2000; Kaestner, 1999). This supports the investigation carried out by The International Labour Organisation (ILO) involving Poland, Sri Lanka, Egypt, Namibia, and Mexico in which drug abuse has a negative influence on the economic performance of the affected country and its citizens. Buddy (2020) in his study also demonstrated that substance abuse among workers could endanger public safety, diminish job performance, loss productivity, theft, and fatalities, and thus, affect the performance of the economy as a whole.

In a like manner, according to the National Safety Council, the U.S. loses an estimated \$74 billion annually in lost work productivity das a result of alcohol intake, from absenteeism, low output, and premature retirement to withdrawal from work, death, or little earning prospect. Since small and medium-sized businesses may not have activities to fight alcohol consumption, they are more likely to employ workers who struggle with alcohol use than a larger business. In some countries, drug activities make users reduce their thought about their predicaments. This work adopts the (ILO) studies in which drug abuse has a negative impact on national productivity.

\subsection{Empirical Review}

Far-reaching econometric models have also been developed and employed in establishing the impact of substance abuse on macroeconomic variables such as human capital, productivity, employment status, poverty labour supply, and wages. For instance, Kaestner (1999) used the Two- equation model to evaluate the effect illicit drug use has on the wages of workers. His result has a stable and supportive finding in line with earlier researches, and the study concluded that illicit drug use has a direct consequence on workers' wages. The longitudinal estimates which control for unobserved heterogeneity in the sample are mixed among men. However, estimated wage influences of marijuana, as well as cocaine use, are indirect. The finding also revealed that its influence on cocaine consumption remains directly huge amongst women. This finding is an indication that the misuse of drugs is gender-sensitive.

Terza and Peter (2007) examined the effects of substance abuse in job qualities and productivity employing the 1992 National Longitudinal Alcohol Epidemiological Survey (NLAES), established from their finding that substance abuse is not exogenous, has a significant negative impact on the likelihood of white-collar employed workers but the finding indicated an opposite influence on a part-time job, since such people will only have income intermittently and not on regular bases. Their result also showed that illicit drug use is income elastic as it could differentiate between those on regular salaries and those on part-time wages.

Roldes (2014). employed cost estimate methodology to determine the social cost of drug abuse in Australia. The drugs examined are alcohol, Cannabis, Opiates, Amphetamines, Cocaine, and Hallucinogens, among others. The study reported that the estimated cost of drug abuse, including licit and illicit substance, was equivalent to 4.8 percent of total expenditure.

Ijie and Babalola (2020), using the Techniques of Auto-Regressive Distributed Lag (ADRL) Model, investigated Government Expenditure on Substance Abused Persons and Economic Growth in Nigeria, 1993-2017. The bound test result indicates that there is a long-run positive effect of government expenditure on substance abuse on the real growth rate.

\section{METHODOLOGY}

\subsection{Model Specification}

In line with Cuddington (1993) model, the functional relationship between economic growth and substance abuse effect can be modeled as:

$\mathrm{GDPgr}=f(\mathrm{SAP}, \mathrm{RHB})$

Where: 
GDPgr is the growth rate of real GDP.

SAP is the Substance Abuse Prevalence rate.

RHB is Rehabilitated individuals on substance abuse.

Transforming equation 1 into an econometric model, equation 2 was derived as

$\mathrm{GDPgr}=\mathrm{b}_{\mathrm{o}}+\mathrm{b}_{1} \mathrm{SAP}+\mathrm{b}_{4} \mathrm{RHB}+\mathrm{Ui}$

Empirically, the regression equation for estimating the impact of substance abuse on economic growth can be modeled in logarithm form as follows

$\operatorname{LogGDPgr}=b_{o}+b_{1} \log S A P+b_{2} \log R H B+U i$

And all variables are as previously defined, except $=b_{0}$, as constant, $b_{1}-b_{2}$ are parameters for estimation and $U_{i}$ as white noise, the error disturbance variable representing all other factors affecting GDP growth rate not captured in the model respectively.

\subsection{Sources of Data}

Secondary data was employed. The data for this study was from NDLEA Annual Report and Drug Data Collection Research. Other sources were the National Bureau of Statistics (NBS), Federal Ministry of Finance annual budget as well as other relevant government agencies in substance abuse data collection. The reason for the use of secondary data is because of the fact that such data have to be obtained over a long period of time (1993-2017). The year 1993 is chosen as the base year of the study because it was the year when the Federal Government made a concerted effort and legislated on the control of illicit drugs. All the variables in the data set are first transferred into the natural logarithm for obvious statistical reasons of standardization, equalization of the variables, and removal of trends. The study spans through 1993-2017 and, in this case, consists of 25 yearly observations.

\subsection{Description of Variables}

Gross Domestic Product Growth Rate (GDPgr). GDP is the total income that accrues on the production of goods and services in the country over a period of one year. This represents the output of the economy. (GDP gr) measures how fast the economy is growing. The study employs real growth rate, which is measured by nominal GDP deflated by inflation rate serves as a proxy for economic growth.

Substance Abuse Prevalence: Prevalence is the number of cases of a particular disease or disorder occurring in the general population at a given point in time. Substance abuse prevalence is included in the model because it leads to "crowding out" effect of a real Gross Domestic Product, through diminished health status of the entire labour force, losses in production due to substances abuse mortality and morbidity, and lost labour productivity.

Treated \& Rehabilitated Addict (RHBS): The prevalence of treated and rehabilitated (RHBS) addicts is thus included in the model because capacities and abilities (skilled and unskilled) that have been diminished or lost due to abuse effects have been recovered due to professional medical care and rehabilitation and such individuals now live a normal life and contribute to the Real Gross Domestic Product.

\section{RESULTS / ANALYSIS}

\subsection{Summary of Descriptive Statistics Results}

Table 1 presents the descriptive statistics of the dataset with 25 observations. It shows that LRHB has the highest mean value (7.010927), followed by LGDPgr (1.405589) and LSAP (-5.31258), respectively. The distribution shows two different forms of normality according to the Kurtosis result. LGDPgr and LSAP show a leptokurtic distribution as their values are approximately 4, while LRHB shows a platykurtic distribution. The Jarque-Bera statistics show the normality distribution of data. Its probabilities show large values, which means the null hypothesis of the normal distribution of the variables is accepted except for LSAP, whose value is zero. Thus, all variables are normally distributed except for LSAP. The standard deviation shows the rate of volatility. Since we have taken the logarithm of all variables, the volatility is already reduced. On Table 1, the highest standard deviation figure is that of LRHB (1.334).

Table 1

Descriptive Statistics Results

\begin{tabular}{lccc}
\hline & LGDP_GR & LRHB & LSAP \\
\hline Mean & 1.405589 & 7.010927 & -5.31258 \\
\hline Median & 1.586658 & 7.282761 & -5.27818 \\
\hline Maximum & 3.518559 & 8.884333 & -4.60685
\end{tabular}




\begin{tabular}{lccc}
\hline Minimum & -0.74605 & 4.691348 & -8.16024 \\
\hline Std. Dev. & 0.899243 & 1.334178 & 0.835194 \\
\hline Skewness & -0.41576 & -0.27341 & -1.90473 \\
\hline Kurtosis & 3.963945 & 1.702875 & 6.995879 \\
\hline Jarque-Bera & 1.553075 & 1.898982 & 29.20908 \\
\hline Probability & 0.459996 & 0.386938 & 0 \\
\hline Sum & & & -122.189 \\
\hline Sum Sq. Dev. & 32.32854 & 161.2513 & 15.34607 \\
\hline Observations & 17.79005 & 39.16067 & 23 \\
\hline
\end{tabular}

Source: Author's computation from E-Views 9

\subsection{Result of Correlation Matrix}

Table 2 presents the relationship that exists within the variables. The result shows that LGDPgr has a 31.1 percent positive relationship with LRHB, while LGDPgr has a 29.5 percent positive relationship with LSAP. These are both weak, except for the relationship between LSAP and LRHB, which is quite high to positive 80.5 percent. Since the relationship does not imply causality, the study went further to make more analysis with econometric tools based on the model of the study.

Table 2

Correlation Matrix Result

\begin{tabular}{llcc}
\hline & LGDP_GR & LRHB & LSAP \\
\hline LGDP_GR & 1 & 0.310564 & 0.295386 \\
\hline LRHB & 0.310564 & 1 & 0.804988 \\
\hline LSAP & 0.295386 & 0.804988 & 1
\end{tabular}

\section{Source: Output from E-Views version 9.}

\subsection{Unit Root Test Result}

The two test statistics used are Augmented Dickey-Fuller (ADF) and Phillip Peron (P.P.). The null hypothesis of both tests is that the variable has a unit root. Unit root tests results are presented on Tables $3(\mathrm{~A} \& \mathrm{~B})$.

Table 3A

ADF Test Result

\begin{tabular}{lllll}
\multicolumn{1}{c}{ Variables } & \multicolumn{1}{c}{ At Level } & Probability & At $\mathbf{1}^{\text {st }}$ Diff. & Probability \\
\hline LGDP_GR & $-3.805104 * *$ & 0.0133 & - & - \\
\hline LRHB & -1.629741 & 0.4526 & $-6.542821 * * *$ & 0.0000 \\
\hline LSAP & $-5.503084 * * *$ & 0.0002 & - & - \\
$* * *$ significant at $1 \%$. & & & \\
$* *$ significant at $5 \%$. & & & \\
\hline
\end{tabular}

Source: Output from E-Views version 9.

The two statistics show that LGDPgr and LSAP are stationary at the level at 5\% and 1\% level of significance. However, LRHB is nonstationary at level but first difference. 


\section{Table 3B}

P.P. Test Result

\begin{tabular}{llccc}
\hline Variables & At Level & Probability & At $\mathbf{1}^{\text {st }}$ Diff. & Probability \\
\hline LGDP_GR & $-2.818859 *$ & 0.0735 & - & - \\
\hline LRHB & -1.552378 & 0.4906 & $-7.139377 * * *$ & 0.0000 \\
\hline LSAP & $-5.503084 * * *$ & 0.0002 & - & -
\end{tabular}

$* * *$ significant at $1 \%$.

$* *$ significant at $5 \%$.

Source: Output from E-Views version 9.

Since these variables were not integrated of the same order, the Autoregressive Distributed Lag (ARDL) model was employed. This technique called for lag selection order before employing it for the analysis. The result is presented below.

\subsection{Results of Selection Order of Model.}

Table 4 presents findings of model selection criteria of twenty possible models using Akaike Information Criteria (AIC), Breusch Information Criteria (BIC), Hannan Quinn (H.Q.), and adjusted R-square.

Table 4

Model Selection Criteria

\begin{tabular}{|c|c|c|c|c|c|c|}
\hline Model & $\log \mathrm{L}$ & AIC* & $\mathrm{BIC}$ & HQ & Adj. R-sq & $\begin{array}{l}\text { ARDL } \\
\text { Specification }\end{array}$ \\
\hline 1 & -8.757522 & 2.262621 & 3.008709 & 2.424541 & 0.392943 & $(4,4,4)$ \\
\hline 2 & -10.529452 & 2.336138 & 3.032487 & 2.487264 & 0.384012 & $(4,4,3)$ \\
\hline 3 & -11.411963 & 2.324949 & 2.971558 & 2.465280 & 0.413751 & $(4,4,2)$ \\
\hline 4 & -16.348692 & 2.699875 & 3.296745 & 2.829411 & 0.166090 & $(4,4,1)$ \\
\hline 5 & -17.062589 & 2.672627 & 3.219758 & 2.791369 & 0.196678 & $(4,4,0)$ \\
\hline 6 & -11.069251 & 2.387548 & 3.083896 & 2.538673 & 0.351517 & $(4,3,4)$ \\
\hline 7 & -11.454772 & 2.329026 & 2.975635 & 2.469357 & 0.411356 & $(4,3,3)$ \\
\hline 8 & -12.373631 & 2.321298 & 2.918168 & 2.450834 & 0.428909 & $(4,3,2)$ \\
\hline 9 & -16.350803 & 2.604838 & 3.151969 & 2.723580 & 0.249330 & $(4,3,1)$ \\
\hline 10 & -17.122099 & 2.583057 & 3.080449 & 2.691004 & 0.265557 & $(4,3,0)$ \\
\hline 11 & -11.962322 & 2.377364 & 3.023973 & 2.517695 & 0.382203 & $(4,2,4)$ \\
\hline 12 & -12.822176 & 2.364017 & 2.960887 & 2.493553 & 0.403984 & $(4,2,3)$ \\
\hline 13 & -12.845972 & 2.271045 & 2.818176 & 2.389786 & 0.462369 & $(4,2,2)$ \\
\hline 14 & -16.474946 & 2.521423 & 3.018815 & 2.629370 & 0.309456 & $(4,2,1)$ \\
\hline 15 & -18.005199 & 2.571924 & 3.019576 & 2.669076 & 0.267688 & $(4,2,0)$ \\
\hline 16 & -12.325892 & 2.316752 & 2.913622 & 2.446288 & 0.431500 & $(4,1,4)$ \\
\hline 17 & -12.867811 & 2.273125 & 2.820256 & 2.391866 & 0.461249 & $(4,1,3)$ \\
\hline 18 & -12.888691 & 2.179875 & 2.677267 & 2.287822 & 0.509252 & $(4,1,2)$ \\
\hline
\end{tabular}




\begin{tabular}{lllllll}
\hline 19 & -17.933915 & 2.565135 & 3.012787 & 2.662287 & 0.272643 & $(4,1,1)$ \\
\hline 20 & -18.869338 & 2.558985 & 2.956898 & 2.645342 & 0.266034 & $(4,1,0)$
\end{tabular}

Source: Author's Extract from E-views 9.

Of all these models, model eighteen with $\operatorname{ARDL}(4,1,2)$ was selected since it has the lowest values of AIC (2.18), BIC (2.68) and H.Q. (2.29) and the highest Adjusted R-sq (0.51). This model (ARDL, 4, 1, 2) was employed for the whole study.

\subsection{Result of ARDL}

Table 5 shows the result of ARDL $(4,1,2)$ in the short run. From Table 5, the impact of LGDPgr spread over four-lag periods shows that they have a positive effect on the present growth rate. Still, their impacts are not significant as indicated by their standard errors $(0.188,0.194,0.240)$, t-statistics $(0.59,1.59,1.40)$ and the probability values $(0.567,0.141,0.18)$. However, at fourth-lag period, the impact of LGDPgr on itself is significant at 1 percent level of significance.

Table 5

Result of ARDL $(4,1,2)$ with LGDPgr as the Dependent Variable.

\begin{tabular}{|c|c|c|c|c|}
\hline Variable & Coefficient & Std. Error & t-Statistic & Prob.* \\
\hline LGDP_GR(-1) & 0.110759 & 0.187737 & 0.589967 & 0.5671 \\
\hline LGDP_GR(-2) & 0.307572 & 0.193863 & 1.586543 & 0.1409 \\
\hline LGDP_GR(-3) & 0.336972 & 0.240332 & 1.402106 & 0.1885 \\
\hline LGDP_GR(-4) & 0.935405 & 0.251551 & 3.718547 & 0.0034 \\
\hline LSAP & -0.724082 & 0.960630 & -0.753757 & 0.4668 \\
\hline $\operatorname{LSAP}(-1)$ & -2.857455 & 0.795206 & -3.593352 & 0.0042 \\
\hline LRHB & 0.561120 & 0.320902 & 1.748569 & 0.1082 \\
\hline LRHB(-1) & 0.935473 & 0.355260 & 2.633209 & 0.0233 \\
\hline LRHB(-2) & -0.692013 & 0.265655 & -2.604931 & 0.0245 \\
\hline $\mathrm{C}$ & -25.25312 & 6.851493 & -3.685783 & 0.0036 \\
\hline
\end{tabular}

\begin{tabular}{lccc}
\hline R-squared & 0.730088 & & \\
\hline Adjusted R-squared & 0.509252 & Akaike info criterion & 2.179875 \\
\hline S.E. of regression & 0.617623 & Schwarz criterion & 2.677267 \\
\hline Sum squared resid & 4.196034 & Durbin-Watson stat & 2.726504 \\
\hline Log-likelihood & -12.88869 & & \\
\hline F-statistic & 3.306010 & & \\
\hline Prob(F-statistic) & 0.032859 & & \\
\hline
\end{tabular}

Source: Author's Extract from E-views 9.

Substance abuse prevalence (LSAP and LSAP (-1)) shows the correct negative sign (-0.724 and -2.857$)$, which is in line with theory, means that at present period (LSAP), one percent increase in LSAP, on the average, would lead to 0.724 percent decrease in LGDPgr. However, the impact is not significant, as shown by all three statistics of standard error, t-statistics, and probabilities. At one-lag period, LSAP (-1), one percent increase in LSAP, on average, leads to 2.86 percent decrease in LGDPgr, and its impact is quite significant with deficient standard error (0.8) and high t-statistics (-3.59). Its probability (0.0042) indicates that the impact is significant at 1 percent level of significance. The coefficients of LRHB show a positive impact on LGDPgr for present and one-lag periods, which is in line with the a priori expectation, except for a two-lag period, which shows an 
unexpected negative sign. The lag periods of LRHB are both significant at 5 percent level of significance as the probabilities show. Since LRHB (-2) is not in line with theory, it is concluded that LRHB (-1) has a significant positive impact on LGDPgr. By implication, a one percent increase in LRHB at the previous year, on average, leads to a 0.94 percent increase in LGDPgr.

The $\mathrm{R}^{2}(0.73)$, which shows the percentage of variation explained by the independent variables, indicates that about 73 percent of variations in LGDPgr is explained in the model. The Fisher's statistics shows 3.31 value with a probability value of 0.03, meaning that the F-statistics is significant at 5 percent level. D.W. statistics (2.7) indicates the presence of serial correlation.

\subsection{Result of ARDL Bound Test}

Table 6 showcases the result of the ARDL bound test, whose essence was to see whether there exists a long-run impact of the two explanatory variables (LSAP and LRHB) on LGDPgr. From the Table, the F-statistics value (5.05) does not exceed the 11 bound (6.36) at 1 percent level of significance, meaning that there is no long-run effect of the explanatory variables on the dependent variable, thus the study could not go further to analyze the long-run impact of the model. This is similar to the finding of Ijie and Babalola (2020).

Table 6

ARDL Bound Test

\begin{tabular}{lccc} 
& Test Statistic & Value & $\mathrm{k}$ \\
\hline F-statistic & 5.048940 & 2 & \\
\hline
\end{tabular}

\begin{tabular}{lcc}
\hline \multicolumn{2}{l}{ Critical Value Bounds } & \\
\hline Significance & I0 Bound & I1 Bound \\
\hline $10 \%$ & 3.17 & 4.14 \\
\hline $5 \%$ & 3.79 & 4.85 \\
\hline $2.5 \%$ & 4.41 & 5.52 \\
\hline $1 \%$ & 5.15 & 6.36
\end{tabular}

Source: Author's Extract from E-views 9.

\subsection{Result of Wald Test}

Table 7 presents the results of the Wald test, which is basically to check for the presence of a redundant variable(s) in the model employed. Using the rule of thumb for standard error that, when it is greater than half the coefficient, the null hypothesis is accepted, among the two variables, broken (through lagging) into the five variables, only LRHB (at present period) shows sign of redundancy since its standard error (0.32) is quite higher than half of its coefficient $(0.56)$. Therefore, other variables are quite relevant in affecting the dependent variable (LGDPgr), though in the short run.

Table 7

Wald Test

\begin{tabular}{llcc}
\hline Test Statistic & Value & df & Probability \\
\hline F-statistic & 4.719911 & $(5,11)$ & 0.0151 \\
\hline Chi-square & 23.59956 & 5 & 0.0003
\end{tabular}

Null Hypothesis: $C(5)=0, C(6)=0, C(7)=0, C(8)=0, C(9)=0$

Null Hypothesis Summary:

\begin{tabular}{lcc}
\hline Normalized Restriction $(=0)$ & Value & Std. Err. \\
\hline LSAP $=\mathrm{C}(5)$ & -0.724082 & 0.960630 \\
\hline LSAP $(-1)=\mathrm{C}(6)$ & -2.857455 & 0.795206 \\
\hline
\end{tabular}




\begin{tabular}{lcc}
\hline LRHB $=\mathrm{C}(7)$ & 0.561120 & 0.320902 \\
\hline LRHB $(-1)=\mathrm{C}(8)$ & 0.935473 & 0.355260 \\
\hline LRHB $(-2)=\mathrm{C}(9)$ & -0.692013 & 0.265655
\end{tabular}

Source: Author's Extract from E-views 9

\subsection{Result of Residual Diagnosis}

Figure 1 presents the normality test of residual diagnosis of the model employed. The standard deviation (0.458) shows approximately close to zero deviation, which is quite good. It shows a mild negative skewness, which is also almost zero. The Kurtosis shows approximately 3.0, a mesokurtic distribution which indicates a normal distribution. Finally, the Jarque-Bera is 0.15 with a probability (0.93), meaning the null hypothesis (of normality) should be accepted.

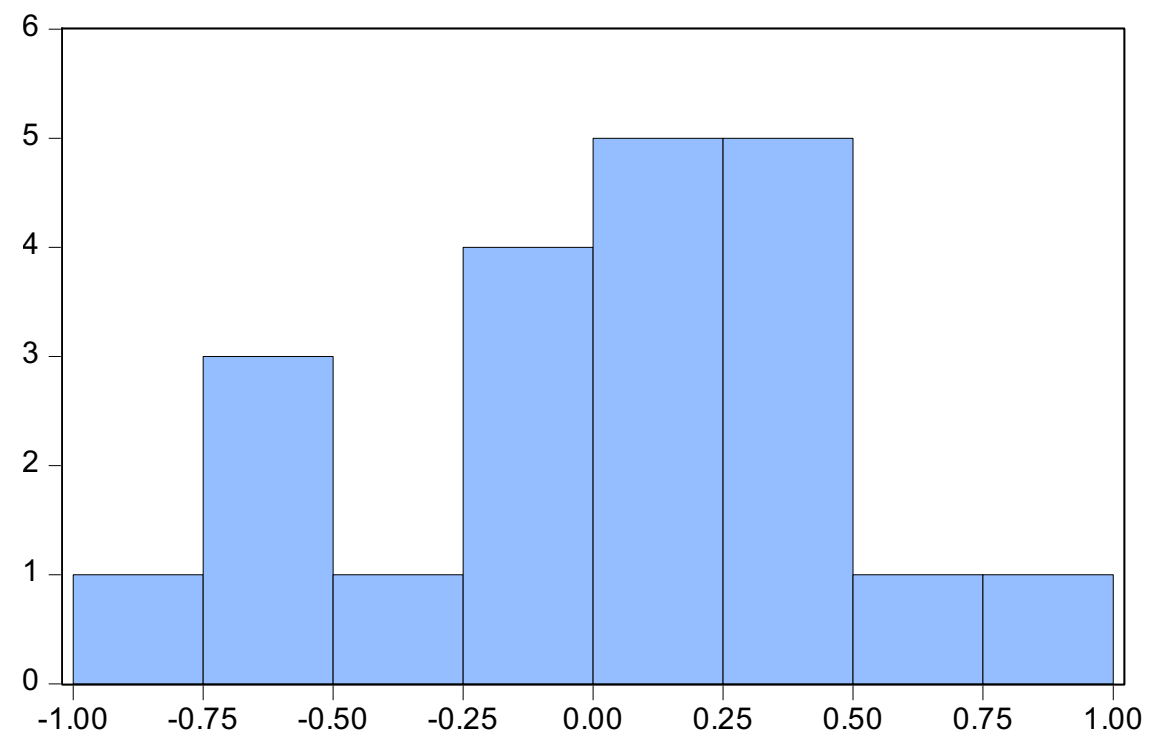

\begin{tabular}{|lr|}
\hline \multicolumn{2}{|l}{ Series: Residuals } \\
Sample 1997 2017 \\
Observations 21 \\
Mean & $4.24 \mathrm{e}-15$ \\
Median & 0.049585 \\
Maximum & 0.952846 \\
Minimum & -0.909594 \\
Std. Dev. & 0.458041 \\
Skewness & -0.139632 \\
Kurtosis & 2.685989 \\
& \\
Jarque-Bera & 0.154518 \\
Probability & 0.925650 \\
\hline
\end{tabular}

Figure 1: Test of Normality of the Residuals

Source: Author's Extract from E-views 9.

\section{DISCUSSION}

The study is on the effect of substance abuse on economic performance in Nigeria for the period between 1993 and 2017 . It made use of substance abuse prevalence (SAP) and rehabilitated individuals (RHB) as the explanatory variables and real growth rate (GDPgr) as a proxy to economic performance and dependent variable.

The first objective, which is germane to this study, was to investigate the impact of substance abuse captured by substance abuse prevalence (SAP) on economic performance proxy of the real growth rate in Nigeria. The result of our correlation matrix showed that substance abuse prevalence (SAP) has a positive relationship with the actual growth rate (GDP_GR). Since correlation does not imply causality, the study went further to analyze the effect of substance abuse prevalence employing the ARDL technique. The ARDL cointegration result showed that in the short run, substance abuse prevalence had a significant negative impact on real economic growth. However, the ARDL bound test result indicated that there was no long-run effect of substance abuse prevalence on the actual growth rate. This implies that the more the government spends on curbing (reducing) the act of substance abuse prevalence in Nigerian, the more people are efficient at work, which will improve productivity and the economic growth. This finding supports the study carried out by the International Labour Organization (ILO), involving Egypt, Mexico, Namibi, Poland and Sri Lanka in which drug abuse has a direct negative influence on the economic performance of the affected country citizen including the youths.

Objective two was set to examine the effect of RHB on the real growth of the RaofNigeria's economy. The result of our correlation matrix indicated that RHB had a weak positive relationship with the real growth rate. The ARDL cointegration result indicated that RHB had a post short-runt run impact on GDP_GR and significant at 5 percent level. Meaning that increase in 
RHB would also invariably increase the value of the real growth rate of the economy since these people will be more efficient at wor,k thereby increasing productivity. This is also in line with a priori expectation of the investigation.

\section{CONCLUSION}

The objective of this study is to investigate the effect of substance abuse on the real growth rate in Nigeria between 1993 and 2017. The study specifically examined the short and long-run impact of substance abuse prevalence and rehabilitated individual drug addicts on the real growth rate on the Nigerian economy.

Previous studies on illicit drug abuse were reviewed on its conceptual, theoretical, and empirical forms. The review of various theoretical frameworks gave us the approach to formulating a functional relationship between the variables in line with the objectives developed in the study. Time-series data were sourced from the National Drug Law Enforcement Agency (NDLEA), National Bureau of Statistics (NBS), Federal Ministry of Finance, and other relevant agencies. Unit Root tests were carried out on the data with all data integrated of order zero (0) except for the rehabilitated individual drug addicts that were of order $1(0)$. The models were then analyzed using the ARDL co-integration/bound test techniques. In between, correlation analysis was carried out.

The study found out that substance abuse and rehabilitated drug individuals have a significant impact on economic growth. While substance abuse had a considerable negative effect, rehabilitated individual drug addict's ha ad significant positive effects. However, in the long run, there was no indication of significant effects on the Nigeria's economy.

\section{LIMITATION AND FUTURE RECOMMENDATIONS}

The primary area for further studies is the area of the methodology used. Researchers could make use of econometric tools like logit and probit models to capture the possibilities involved in the study. Also, more variables such as crime rate and number of imprisoned people due to drug use could be added to the model.

1) Combating the menace of drug abuse prevalence and trafficking needs the co-operative of all, to that extent, government and non-government organizations at both local and international levels must network to ensure effective control.

2) Adequate funds should be made available to government organizations involved in drug demand reduction activities.

3) Employment opportunities should be created by the government to get users/ traffickers out of the illegal business.

4) Massive preventive drug abuse education and enlightenment emphasizing a healthy lifestyle should be embarked upon frequently due to the increasing number of youths getting involved in drug abuse and illicit drug trafficking.

\section{REFERENCES}

Botvin, G. J., Baker, E., Dusenbury, L., Botvin, E. M., \& Diaz, T. (1995). Long-term follow-up results of a randomized drug abuse prevention trial in a white middle-class population. Jama, 273(14), 1106-1112.

Buddy, T. (2020). The Dangers of Substance abuse in the Workplace. Verry Wellmimd. Retreived from verrywellmind.com/substance.

Eric, S., Lynda, R., Xiaodi, X., \& Jurgen, R. (2000). The cost of Substance Abuse in Canada. Canadian Center on Substance Abuse (CCSA). Retrieved from https://www.issup.net/about-issup/international-partners/ccsa

Forbes Africa (2017). The High Price of Addiction. Forbes Africa. Retrieved from https://www.forbesafrica.com/focus/2017/09/05/high-price-addiction/

GFI (2017). Global Financial Index. Global Financial Inclusion. Retrieved from https//globalfindex.worldbank.org.

Goplerud, E., Hodge, S., \& Benham, T. (2017). A substance use cost calculator for U.S. employers with an emphasis on prescription pain medication misuse. Journal of occupational and environmental medicine, 59(11), 1063.

Ijie, I. J. (2016). The Social and Health Effects of Drug Abuse. A lecture presented at Guard Brigade Headquarters to Personnel of 7 Guards Battalion and their families, Abuja, FCT. Development. www.incb.org>English Retrieved on 11-02-18

Ijie, I. J. (2019). Government Expenditure on Substance Abuse Persons and Economic Growth: 1993-2017. Unpublished PhD Thesis submitted to the Department of Economics University of Abuja.

Ijie, I. J., \& Babalola, A. (2020). Substance Abuse, Labour Force and Economic Growth in Nigeria: An Empirical Analysis. Scholars' Press, USA.

INCB (2012). Economic Consequences of Drug Abuse. National Budget for Agriculture and Rural. Retrieved from https://www.incb.org/documents/Publications/AnnualReports/Thematic_chapters/English/AR_2013_E_Chapter_I.

Kaestner, R. (1999). Does drug use cause poverty? In the Economic Analysis of Substance Use and Abuse: An Integration of Econometric and Behavioral Economic Research (pp. 327-368). University of Chicago Press.

Kristin, B., Synnove, M. I., \& Torleif, H. (2018). Alcohol Related Absence and Presenteeism: Beyond Productivity Loss. International Journal of Drug Policy. Vol. 58 Pg. 71-77.

Mitchel, O. (2015). Drug Abuse Enlightenment. NDLEA Public Relation Office, on the occasion of a public lecture on,NDLEA Headquarters, Ikoyi, Lagos.

Murray, D. M. (1998). Design and analysis of group-randomized trials (Vol. 29). Oxford University Press, USA. 
NDCMP (1999) National Drug Control Master Plan NDLEA 1999. Retrieved from https://www.unodc.org/documents/nigeria/Drug-response/NDCMP_book

NDLEA (2015). Drug Seizure Report. National Drug Law Enforcement Agency. Rētrieved from https://ndlea.gov.ng/annualreports/

NDLEA Drug Data Report (2017). Drug Use Survey. Retrieved from https://ndlea.gov.ng/annual-reports/

NIDA (2018). Drug Misuse and addiction. National Institute on Drug Abuse. Retrieved from www.drugabuse.gov $>$ drugs

Roldes, M. I. (2014). The Longitudinal Effects of Drug Use on Productivity Status of Non-Metropolitan African American Young Adults. SAGE Journals. Retrieved from https://journals.sagepub.com/doi/abs/10.1177/0047237915573524

South African Depression and Anxiety Group (2013). Retrieved from www.sadag.org

Terza, V. J. \& Peter, B. V. (2007). The Effects of Substance Abuse on Employment Status. Robert Wood Johnson Foundation Substance Abuse Policy Research Programe. Retrieved from https://www.rwjf.org/en/library/research/2012/01/substance-abuse-policy-research-program.

UNDCP (2009). United Nation International Drug Control Programme. Retrieved from www.nzdl.org>gsdlmod.

UNODC (2011). United Nation office on Drugs and Crimes World Drug report. Retrieved from https://www.unodc.org/unodc/en/data-and-analysis/WDR-2011.html

UNODC (2017). World Drug Report. United Nation Office on Drugs and Crime. 2017. Retrieved from https://www.unodc.org/wdr2017/field/Booklet_1_EXSUM.pdf

Yomi, K. (2019). A National survey has confirmed the massive scale of Nigeria's Drug problem. QuartzAfrica htts//qz.com $>$ Africa $>$ Nigeria. 